\title{
The Preparation of Iron Oxide Nanoparticles by a Self-combustion Method
}

\section{Ondřej Seibert ${ }^{1}$, Jan Grégr ${ }^{2}$, Pavel Kejzlar ${ }^{1}$}

${ }^{1}$ Department of Material Science, Faculty of Mechanical Engineering, Technical University of Liberec, Studentska 1402/2, 461 17, Liberec, Czech Republic,EU. Email: ondrej.seibert@tul.cz, pavel.kejzlar@tul.cz

${ }^{2}$ Department of chemistry, Faculty of Sciences, Humanities and Education, Technical University of Liberec, Studentska 1402/2, 461 17, Liberec, Czech Republic, EU. Email: jan.gregr@tul.cz

This paper deals with problematic of preparation of iron oxide nanoparticles according to a self-combustion method. Iron oxide nanoparticles can be used e.g. for catalysators and gas sensors or in MRI. The Self-combustion method is based on rapid chemical reaction between a fuel and iron oxide precursor. Glycine, urea and citric acid were used as fuels and iron nitrate nonahydrate was used as an iron oxide precursor. The self-combustion method doesn't require any special equipment, is environment-friendly due to minimize pollution and the results are easily reproducible. The shape, size, and phase of resulting particles were investigated studied using scanning electron microscopy and energy-dispersive analysis.

Keywords: Iron oxide, nanoparticles, synthesis, characterization, microscopy

\section{Introduction}

These days, many researchers are focusing on synthesis, characterization, and application of different nanoparticles. Due to their size, they show many extraordinary properties, which make them potential candidates for usage in many branches and special applications.

Iron oxide nanoparticles, which are topic of this paper, are interesting because of their properties, like magnetism or the reactivity. Also, these nanoparticles are intensively studied because of their wide potential uses in medicine, such as drug delivery [1] or cancer treatment [2]. Another potential usage is related to their adsorption ability of dangerous ions [3]. It may be effectively used for neutralizing the negative impact of toxic pollution like cadmium [3], which is extremely dangerous for the environment, or dye removal from water [4].

There are many ways, how to obtain iron oxide nanoparticles. Very common methods are different kinds of pyrolysis reactions, like ethylene glycol and ferric nitrate pyrolysis [5], or more modifications of the reaction, such as adding citric acid or tartaric acid [6] Quite complicated and expensive method is micelle nanolithography [7]. Another cheap, fast and environmental friendly is selfcombustion method [8]. This method is interesting due to its simplicity and easy reproducibility.

The aim of this research was to prepare and characterize iron oxide nanoparticles using low-cost raw materials and without necessity of usage of any special (and expensive) laboratory equipment, going hand to hand with a minimum ecological burden. The self-combustion method was evaluated as very promising.

\section{Experimental}

As starting materials were used three different fuels and iron nitrate nonahydrate (purity $99.9 \%$ ) as iron oxide precursors. First chosen fuel was citric acid (99.8\%), followed by urea $(99.9 \%)$ and glycine $(99.9 \%)$. All these raw materials are basically cheap and easy to purchase.

All three syntheses were executed according to schema showed in Figure.1.

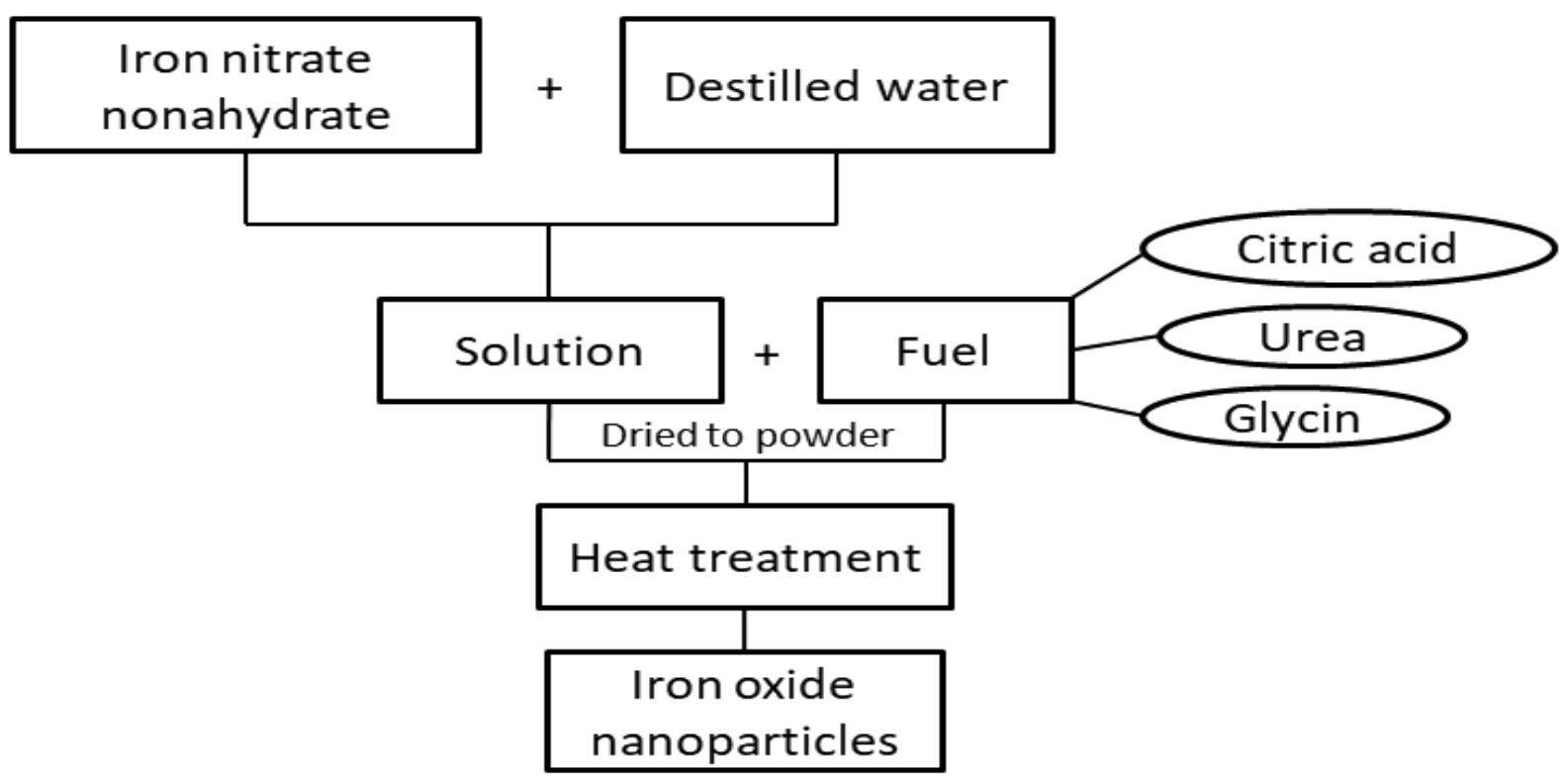

Fig. 1 Schema of self-combustion method 
Firstly, 1 gram of iron nitrate nonahydrate was dissolved in minimum amount of distilled water. As next step was added 1.5 gram of citric acid or $0.7 \mathrm{~g}$ of urea or 1 gram of glycine. All solutions were properly mixed and subsequently dried to a powder. This powder was heat treated for 11 hours up to temperature $650^{\circ} \mathrm{C}$, according to Fig. 2 in the furnace, which led to brown-red powder. During the heat treatment, a rapid reaction between oxidizer (nitrate) and the fuel was observed. This reaction has an indisputable impact on the particle size distribution.

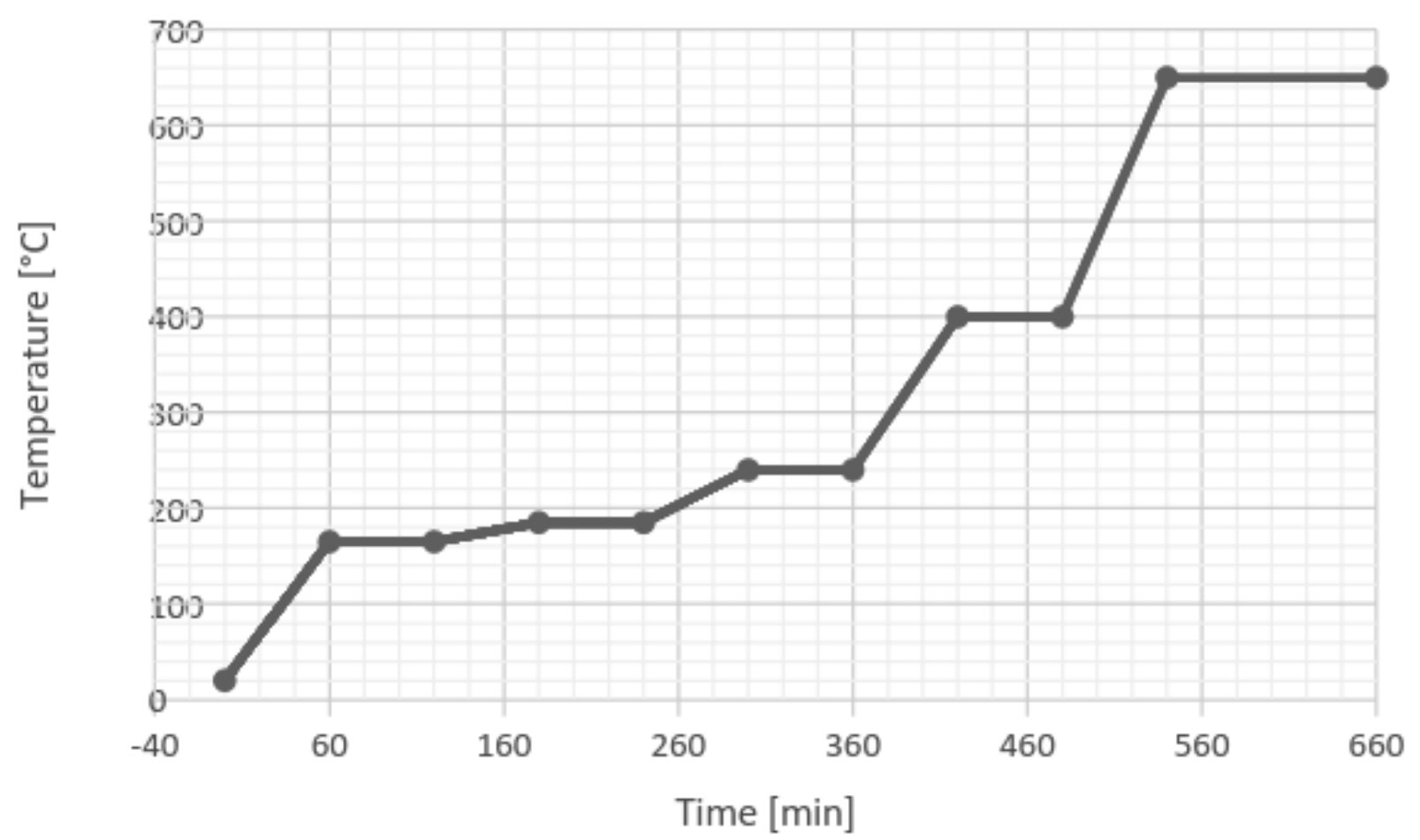

Fig. 2 A graph showing the course of heat treatment

Obtained products were characterized using UHRSEM Zeiss Ultra Plus equipped with an energy-dispersive spectrometer Oxford X-Max 20 for local chemical analysis. SEM images of the structure were taken at accelerating voltage of $2 \mathrm{kV}$ in topographical contrast using InLens secondary electron detector [9]. EDS spectra were acquired at accelerating voltage of $10 \mathrm{kV}$.

\section{Results and discussion}

\subsection{Iron oxide nanoparticles prepared using citric acid}

Citric acid was selected as fuel, based on its potential

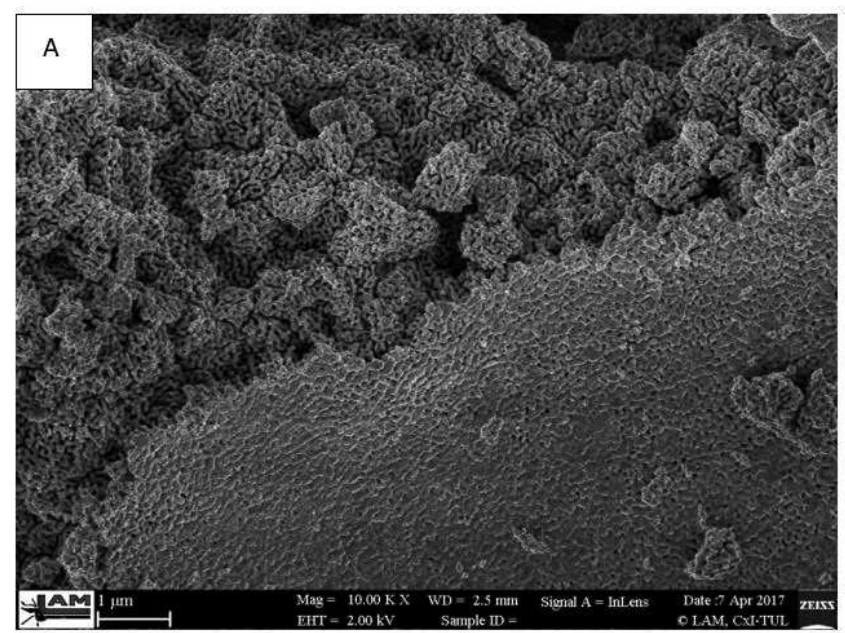

ability to complex $\mathrm{Fe} 3+$ ions well through - $\mathrm{COOH}$ functional group and solid potential for preparation of nanomaterial. Another reason for choosing citric acid was to also to study a fuel which doesn't contain any $\mathrm{H} 2 \mathrm{~N}$ - functional group. After the heat treatment, a rusty powder was obtained in the aluminum oxide crucible. From SEM Figure 3 is clear, that particles form clusters coated by a solid layer. However, we can clearly see a fluffy structure with a high surface area of the fracture. Figure 4 shows the particles in detail. The particles have elongated, branched shape with a diameter size of $60 \mathrm{~nm}$. The EDS spectrum is shown in Fig. 4. It is clear that the chemical composition well corresponds to $\mathrm{Fe} 2 \mathrm{O} 3$ - hematite.

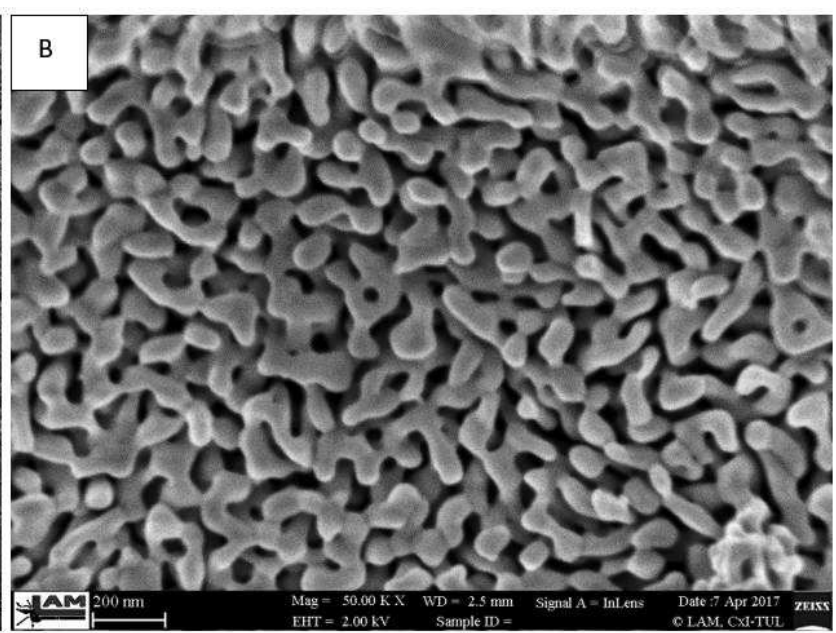

Fig. 3 A) Solid coating around fluffy structure; B) elongated, branched iron oxide nanoparticles 


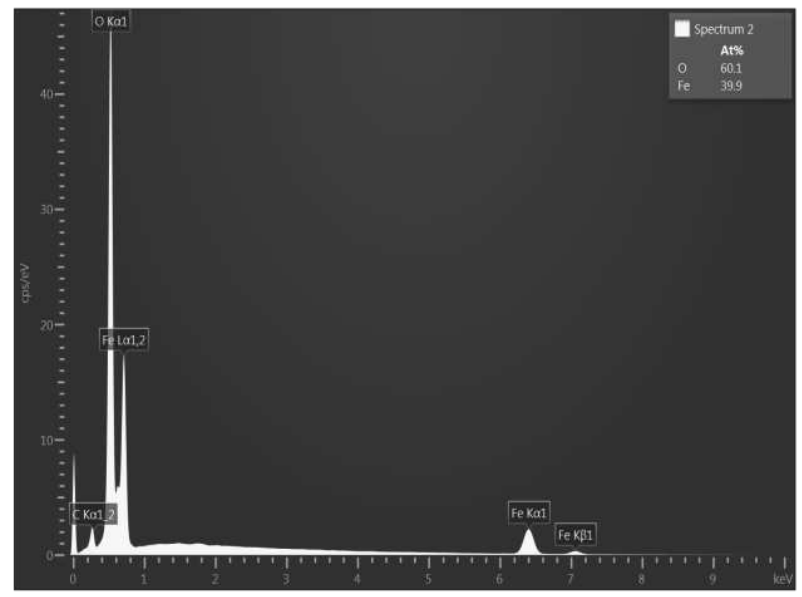

Fig. 4 EDS analysis of iron particles prepared using citric acid
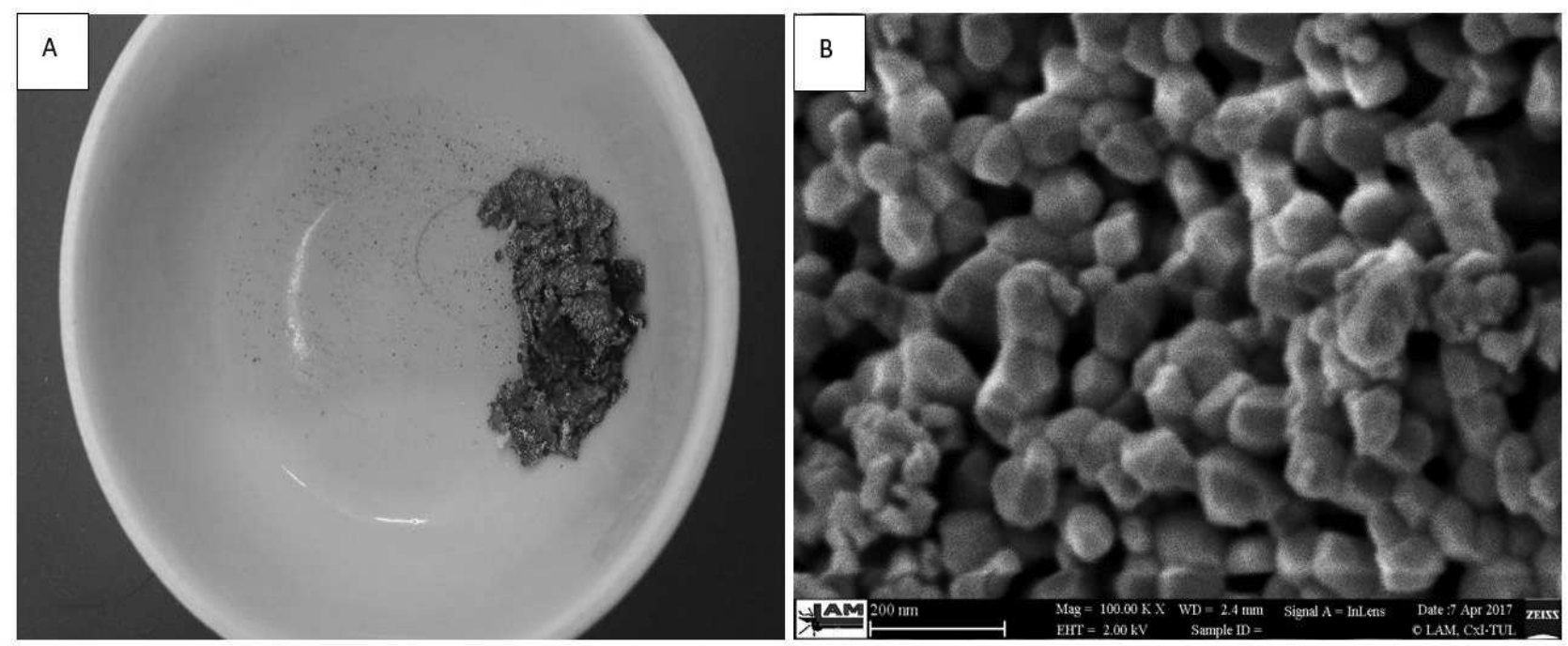

Fig. 5 Urea A) Iron oxide powder after the heat treatment; B) Iron oxide nanoparticles
Fig. 6 EDS analysis of iron particles prepared using urea

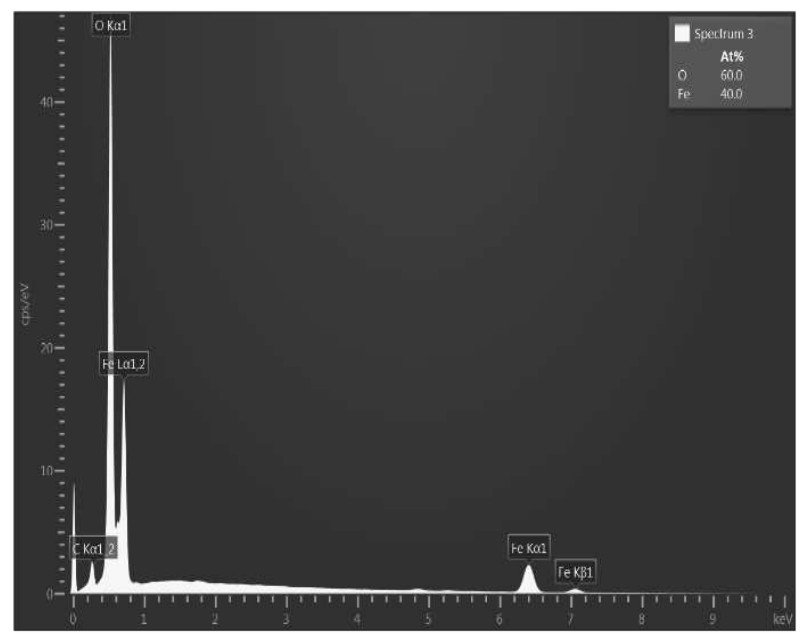

\subsection{Preparation of iron oxide nanoparticles using urea}

Choosing urea as fuel was mainly caused by the presence of two amino-functional groups. These groups are capable to effectively complex iron ions. Fig. 5 A) shows iron oxide powder in aluminum crucible after the heat treatment. It is obvious, that the powder has dark metal shine. Also in this sample, particles are in clusters, but in Fig. 5 B) are clearly spotted well-defined iron oxide nanoparticles, with average size $85 \mathrm{~nm}$. The shape of these particles is $\mathrm{n}$-hedrone, placed in multiple layers. There appears quite a lot of gaps between the particles, which may cause easier separation of particles. The EDS spectrum is shown in Fig. 6. It is clear that the chemical composition well corresponds to $\mathrm{Fe} 2 \mathrm{O} 3$ - hematite.

\subsection{Iron oxide nanoparticles prepared using glycine}

Last used fuel chosen for self- combustion reaction was glycine. Glycine contains both, amino $(\mathrm{H} 2 \mathrm{~N}-)$ and carboxyl (-COOH) functional groups. Because of that, glycine is able to make complex through both of the functional groups, as it is demonstrated on a model in Figure 9. In Figure $7 \mathrm{~A}$ ), there is an iron oxide in glass beaker after the heat treatment. The resulting colour of iron oxide powder is rusty and dark brown. The resulting product's structure, right after taking out of the furnace, is porous. The microstructure of the powder is also porous (Fig. 7 B), with standard walls thickness of $2 \mu \mathrm{m}$. These "walls" have crystalline character. This may be reduced in different heat treatment, change of $\mathrm{pH}$ or glycine concentration. The EDS spectrum is shown in Fig. 8. It is clear that the chemical composition well corresponds to $\mathrm{Fe} 2 \mathrm{O} 3$ - hematite. 


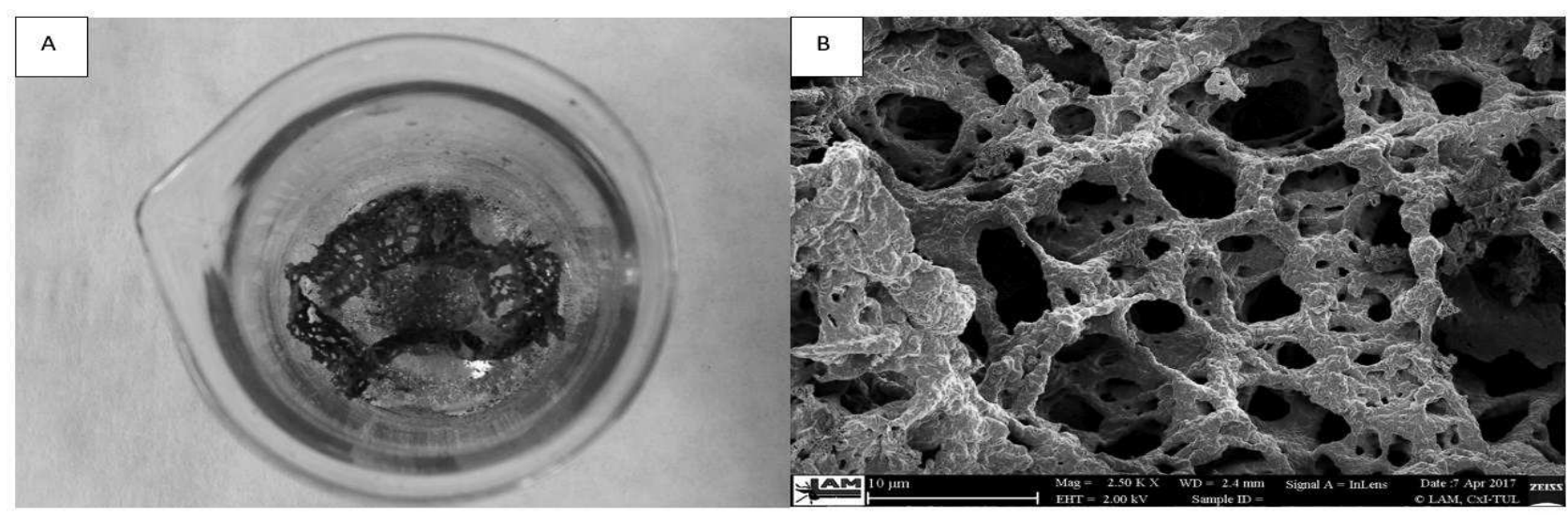

Fig. 7 Glycine A) Iron oxide powder after the heat treatment, porous structure; B) Iron oxide porous structure, detail

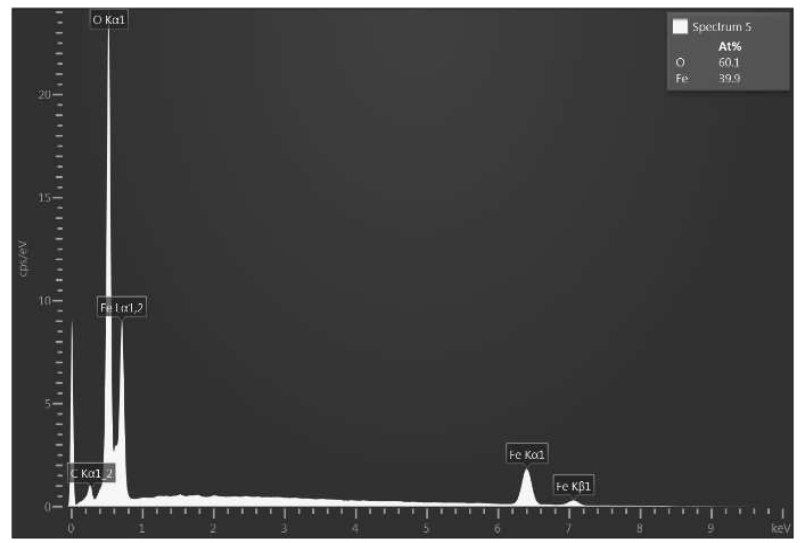

Fig. 8 EDS analysis of iron particles prepared using glycine

\subsection{Mechanism of the self-combustion method}

The principle of the self-combustion method is based on complexation of $\mathrm{Fe} 3+$ ions. It can be supposed that functional groups coming from fuels are bonded to $\mathrm{Fe} 3+$ ions through the nitrogen atom from an amino group and/or oxygen from - $\mathrm{COOH}$ group. Further research to prove this theory is necessary.

Also, reaction equations were estimated (Fig. 10). These equations show stoichiometric balance of reactions. Without any oxygen source from the atmosphere, all nitrogen atoms cannot be oxidized to nitrogen oxide. In this paper, reaction was obtain in atmospheric condition, thus the evaporation of nitrogen oxides is unavoidable. These suggested equations correspond well to results published by Deshpande [10].

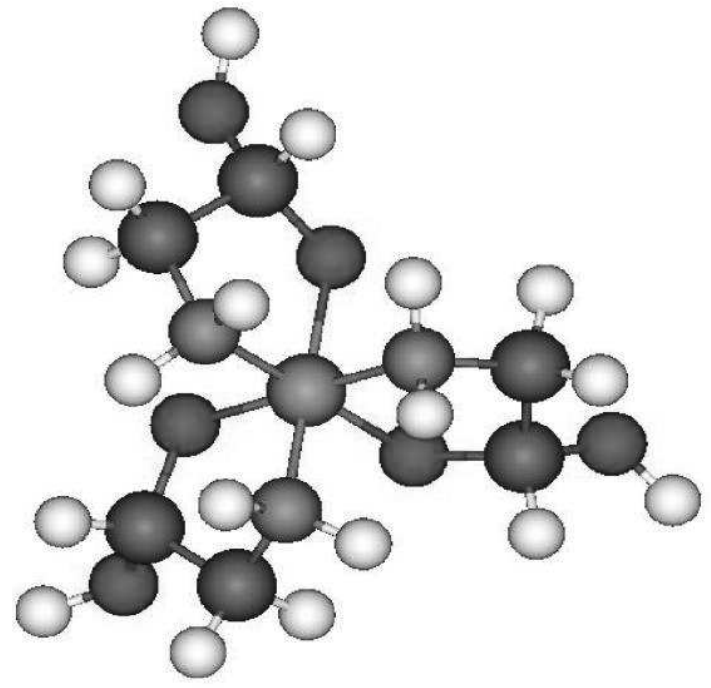

Fig. 9 The model of an iron ion (Fe3+- violet in the middle), surrounded by 3 glycine molecules, which makes stable complex. Red colour = oxygen, blue = nitrogen, grey $=$ carbon, white $=$ hydrogen.

$$
\begin{gathered}
10 \mathrm{CH}_{2} \mathrm{NH}_{2} \mathrm{COOH}+6 \mathrm{Fe}\left(\mathrm{NO}_{3}\right)_{3} \rightarrow 3 \mathrm{Fe}_{2} \mathrm{O}_{3}+14 \mathrm{~N}_{2}+20 \mathrm{CO}_{2}+25 \mathrm{H}_{2} \mathrm{O} \\
5 \mathrm{CO}\left(\mathrm{NH}_{2}\right)_{2}+2 \mathrm{Fe}\left(\mathrm{NO}_{3}\right)_{3} \rightarrow \mathrm{Fe}_{2} \mathrm{O}_{3}+8 \mathrm{~N}_{2}+5 \mathrm{CO}_{2}+10 \mathrm{H}_{2} \mathrm{O} \\
5 \mathrm{C}_{6} \mathrm{O}_{7} \mathrm{H}_{8}+6 \mathrm{Fe}\left(\mathrm{NO}_{3}\right)_{3} \rightarrow 3 \mathrm{Fe}_{2} \mathrm{O}_{3}+9 \mathrm{~N}_{2}+30 \mathrm{CO}_{2}+20 \mathrm{H}_{2} \mathrm{O}
\end{gathered}
$$

Fig. 10 Estimated reaction equations, based on observation of evaporating gasses and measuring final products' weight.

Unlike the temperature profiles published by Deshpande [10] using only $200{ }^{\circ} \mathrm{C}$, our results showed that the temperature over $500{ }^{\circ} \mathrm{C}$ is needed. The temperature of $200{ }^{\circ} \mathrm{C}$ is sufficient only to ignite the reaction, but the resulting products are mostly amorphous [11] and contain high amounts of organic residua. Temperature of $650{ }^{\circ} \mathrm{C}$ was chosen as ideal to make sure all organic compounds are evaporated to the atmosphere and also importantly, the samples were recrystallized to highly crystalline and organic-free phase.
The amount of fuels in this work was higher than stoichiometric. The reason behind is to ensure complete complexation of metallic ions to protect them from rapid growing. Also, fuel that does not participate in complexation process is a source of energy during the selfcombustion reaction. However, the use of higher amount of fuel brings several problems. Worth of point out is definitely sintering of desired nanoparticles. The self-combustion reaction itself produce more energy which is used for particle growth and also, previously mentioned, sinte- 
ring. This fact makes further dispergation more complicated and energy demanding.

\section{Conclusion}

The self-combustion method was successfully used for the synthesis of well-defined iron oxide nanoparticles. Using urea as fuel leads to the production of well-defined polyhedral nanoparticles with average size of $85 \mathrm{~nm}$. Due to the high occurrence of gaps, it is easier to disintegrate the bulks of particles. Elongated, branched iron oxide nanoparticles, with a solid coating of clusters were obtained using citric acid. The synthesis with the use of glycine resulted in porous particles with crystalline walls. All three reactions led to the production of hematite.

Despite the reaction were successful, further research is needed. It is necessary to study in detail the influence of thermal treatment, $\mathrm{pH}$, and concentration of fuels. These may have an impact on the resulting structures, particles shape, and particle size distribution.

Very important fact is high yield. The effectivity of production, compared to theoretical, is around

$90 \%$. This is caused by the absence of any washing of product because every waste component is vaporized during the heat treatment and only pure iron oxide remains. The losses are caused mainly because of manipulation.

To end up with, self-combustion method is very promising, easily reproducible "green" method for producing nanoparticles. There are no toxic waste materials and only negligible pollution caused by vaporized gasses.

\section{Acknowledgement}

This publication was written at the Technical University of Liberec as a part of the project "The study and evaluation of the material's structure and properties " with the support of the Specific University Research Grant, as provided by the Ministry of Education, Youth and Sports of the Czech Republic in the year 2018.

\section{References}

[1] WANG, X., DENG, A., CAO, W., LI, Q., WANG, L., ZHOU, J., HU, B., XING, X. (2018) Synthesis of chitosan/poly (ethylene glycol)-modified magnetic nanoparticles for antibiotic delivery and their enhanced anti-biofilm activity in the presence of magnetic field. Journal of Materials Science, May 2018. Vol. 53, no. 9, pp. 6433-6449.

[2] MENG, Q., RAO, L., ZAN, M., CHEN, M., YU, G., WEI, X., WU, Z., SUN, Y., GUO, S., ZHAO, X., WANG, F., LIU, W. (2018). Macrophage membrane-coated iron oxide nanoparticles for enhanced photothermal tumor therapy. Nanotechnology.Vol. 29, no. 13, p. 134004.

[3] EHRAMPOUSH, M. H., MIRIA, M., SALMANI, H. M., MAHVI H. A. (2015). Cadmium removal from aqueous solution by green synthesis iron oxide nanoparticles with tangerine peel extract. Journal of Environmental Health Science and Engineering, vol. 13 , pp. 84

[4] WANG, J., SHAO, X., ZHANG, Q., TIAN, G., JI, X., BAO, W. (2017). Preparation of mesoporous magnetic $\mathrm{Fe} 2 \mathrm{O} 3$ nanoparticle and its application for organic dyes removal. Journal of Molecular Liquids, Vol. 248, p. 13-18.

[5] CHEN, L., LIN, Z., ZHAO, C., ZHENG, Y., ZHOU, Y., PENG. H., (2011). Direct synthesis and characterization of mesoporous $\mathrm{Fe} 3 \mathrm{O} 4$ through pyrolysis of ferric nitrate-ethylene glycol gel. Journal of Alloys and Compounds, Vol. 509, No 1, pp. L1-L5,

[6] DAVAR, F., HADADZADEH, H., ALAEDINI, S., T. (2016). Single-phase hematite nanoparticles: Non-alkoxide sol-gel based preparation, modification and characterization. Ceramics International, Vol. 42, No. 16, 19336-19342.

[7] BERA, A., BHATTACHARYA, A., TIWARI, N., JHA., S., N., BHATTACHARYYA, D. (2018). Morphology, stability, and X-ray absorption spectroscopic study of iron oxide (Hematite) nanoparticles prepared by micelle nanolithography. Surface Science, Vol. 669, p. 145-153.

[8] WANG, X., QIN, M., FANG, F., JIA, B., WU, H., QU, X., VOLINSKY, A. A. (2018). Solution combustion synthesis of nanostructured iron oxides with controllable morphology, composition and electrochemical performance. Ceramics International, Vol. 44, no. 4, p. 4237-4247.

[9] KEJZLAR, P., ŠVEC, M., MACAJOVÁ, (2014). The usage of backscattered electrons in scanning electron microscopy. Manufacturing Technology. October 2014, Vol. 14, No. 3, p. 333 - 336.

[10] DESHPANDE, K., MUKASYAN, A., VARMA, A., (2004). Direct Synthesis of Iron Oxide Nanopowders by the Combustion Approach: Reaction Mechanism and Properties. Chemistry of Materials. October 2004, Vol. 16, No. 24, p. 48964904.

[11] DHANANJAYA, N., NAGABHUSHANA, H., NAGABHUSHANA, B.H., RUDRASWAMY, B., SHARMA, S.C., SUNITHA, D.V., SHIVAKUMARA, C., CHAKRADHAR, R.P.S., (2012). Effect of different fuels on structural, thermo and photoluminescent properties of Gd2O3 nanoparticles. Spectrochimica Acta Part A: Molecular and Biomolecular Spectroscopy. May 2012, 96, p.532-540 